\title{
EVALUATION OF BEARING RELIABILITY OF COMBINE HARVESTER STRAW CHOPPER
}

\author{
Egle Jotautiene $^{1}$, Antanas Juostas ${ }^{1}$, Algirdas Janulevicius ${ }^{1}$, Aivars Aboltins ${ }^{2}$ \\ ${ }^{1}$ Vytautas Magnus University, Lithuania; ${ }^{2}$ Latvia University of Life Sciences and Technologies, Latvia \\ egle.jotautiene@vdu.lt, antanas.juostas@kesko.lt, algirdas.janulevicius@vdu.lt, \\ aivars.aboltins@inbox.lv
}

\begin{abstract}
In most common cases, combine harvester failure occurs during harvesting the fields. In order to avoid faults, it is necessary to prepare the combine harvester for work in advance. There are many rotating parts in this machine, which work depends on each other. In the case of a unit failure, the machine cannot be operated further. To avoid these problems, it is necessary to find faults and remove them as early as possible. In order to minimize the time for determination of the combine harvester bearing condition, the vibro analytical methods are used to determine the status of the bearings without dismounting the units. This paper provides the research results of the rolling bearing condition of the combine straw chopper using vibration diagnostics. Identification of the vibration sources is based on the Fast Fourier Transform (FFT) spectrum analysis. From the obtained results and data analysis, it can be stated that the average values of vibration velocity (in frequency interval 10$1000 \mathrm{~Hz}$ ) in combination to other measured parameters can be used to assess the combine straw chopper bearing condition. The obvious defects should occur when the amplitude of the vibrations increases, the bearing balls passing through the outer bearing ring, which theoretical frequency equals $f_{R P I}=36 \mathrm{~Hz}$, the inner ring $f_{R P V}=44$ $\mathrm{Hz}$ and the ball defect $f_{R D D}=66.7 \mathrm{~Hz}$. From practical point of view, the use of the vibro analysis technique together with the temperature analysis technique would significantly increase the accuracy for determination of the bearing defect.
\end{abstract}

Keywords: bearing reliability, combine harvester, straw chopper, vibro analysis method.

\section{Introduction}

Each machine or unit during its operation produces various oscillation signals due to different factors: imperfection of the structure, rotor imbalance, friction in the moving chain, defective decontaminating nodes, etc. Oscillation signals from stationary installations are measured by oscillation measuring devices. Subsequently, the data analysed and tested by appropriate methods. This determines the technical condition of the installation or the unit.

The rolling bearing is one of the most important and most widely used components in various rotating machines. Unexpected failures of this element can result in significant material damage and stopping the operation of the machine. The damaged bearing often unbalances the rotor stable axis of rotation. This can create prerequisites for a chain fault reaction across the entire device. It is very important to identify the bearing defects in the earliest possible stage of such failures. Bearing defects in diagnostic methods are extensively researched in recent years. A number of bearings are also used in mobile agricultural machines on tractors, combines, tillage machines. Mainly combine harvesters experience various failures during the harvesting period. The meteorological conditions during harvesting are unstable, so the reliability of the work of the combine mechanisms is very important during the harvesting season. In order to avoid the malfunction of the mechanisms during work, combine harvesters must be prepared beforehand. The check in of each individual unit is a complex and time-consuming process. Before ensure that the bearings are in good condition, they should be disassembled. The most widely used diagnostic methods for bearing technical condition estimation are vibratory, acoustic and thermovisionary [1]. In order to save the consumption for checking the bearing condition of the combine harvesters a vibration analysis method was selected. This vibration determination method is used for diagnosis of bearings on stationary machines.

The principle of operation of this method is based on the friction power of the high frequency incidental oscillation, which is stationary when the bearing defects have not developed. The vibration power remains constant during operation or the bearing check time period. In the case of bearing defects, the oil is squeezed from the contact area of the bearing elements, during this the periodic friction forces change and high-frequency oscillation occurs. This type of vibrations can also occur, if an inadequate (low-viscosity) oil is used, when the film is easily squeezed [2].

The straw chopper is one of the most important units of the combine harvester, which crushes and spreads straw on the stubble. The high speed of the chopper bearings can have a decisive impact on 
the work of the chopper unit and the technical condition of the combine. The most common failures of the rolling bearings are damage of the inner or outer ring of the bearing surface or the rolling elements [3]. Rolling bearings may have abrasive, aerostatic or fatigue abrasion [4].

The purpose of the research is to investigate the current bearing technical condition of the combine straw chopper, without destroying the rigid unit by using the vibro analysis method.

\section{Materials and methods}

For the test the straw chopper right-hand bearings of the Claas brand combine were selected. This company combine harvester straw chopper uses company FAG 20213-K-TVP-C3 closed-type bearings. Bearing dimensions: outer diameter $120 \mathrm{~mm}$, internal diameter $65 \mathrm{~mm}$, width $23 \mathrm{~mm}$.

For the measurements the Adash A4900 Vibrio M oscillation analyser, produced in the Czech Republic, was selected. It uses an external accelerometer with magnetic base. This analyser is designed for technicians, engineers and consultants, who need to assess the technical condition of the rotary machines and their assemblies. The analyser provides oscillation measurements in the three spectrum range. The A4900 Vibrio M device is designed according to ISO 10816-3 vibration testing requirements [5]. This standard covers the main indicators of identification of machine failure: unbalance, incorrect axis alignment, looseness and free play. Early machine diagnosis warns about the possible faults, prevents accidental and costly damage of the machine or its units. Periodic measurement allows ensure a good condition of the machine. For determination of the oscillation level of the straw chopper the Adash bearing oscillation analyser (Fig. 1) was used.

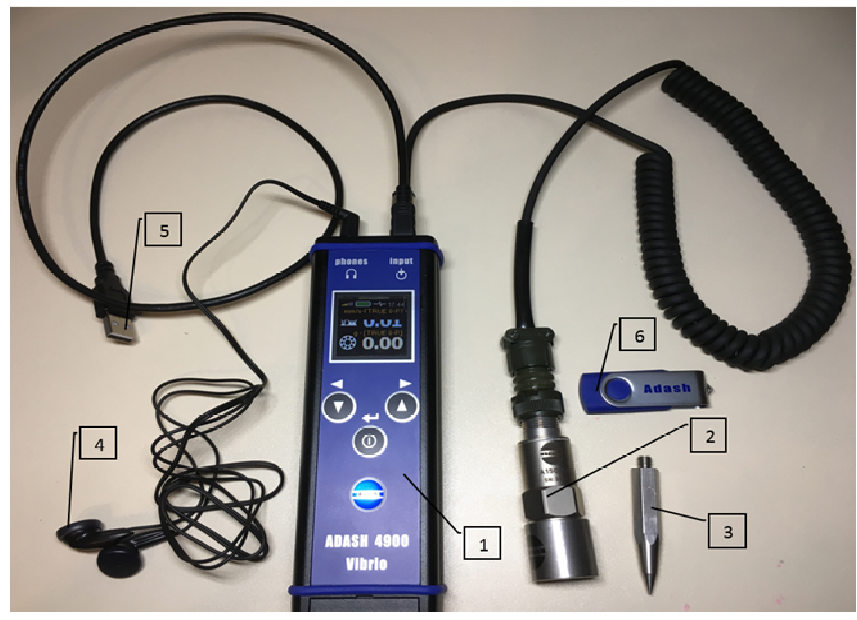

Fig. 1. Vibration analyser A4900 Vibrio M from „Adash” company: 1 - analyser and data collector; 2 - accelerometer with magnetic base; 3 - meassuring tip for manual pressure on the sensor; 4 - headphone set; 5 - USB connection; 6 - USB stick

Temperature measurement is performed with the help of infrared radiation. This is done by a noncontact temperature measuring sensor Adash 4900 [6]. For the measurement data analyses the vibration measuring device Adash 4900 uses the DDS software program. DDS software is based on the creation of a test route tree template. The main part of the software contains the configuration of the model test templates. It is possible to use the principles of test mechanisms that are already designed or made more consistent. DDS Software delivers up to 17 different graphs of the measurement data. In view of the specificity, the structure and other aspects of the machinery being tested, it is possible to choose the graphs, which are most characteristic of the test mode, which allows quickly and accurately detect the testing bearing wear or even a defect.

For the straw chopper bearing vibration measurement the accelerometer has been mounted according to the diagram in Figure 2. The straw chopper of the combine harvester was run at a speed of $3389 \mathrm{rpm}$. To determine which of the accelerometer installation locations provides the most complete information about the bearing condition, the bearing vibration is measured at three different locations according to the radial direction of the straw chopper shaft [7]. 


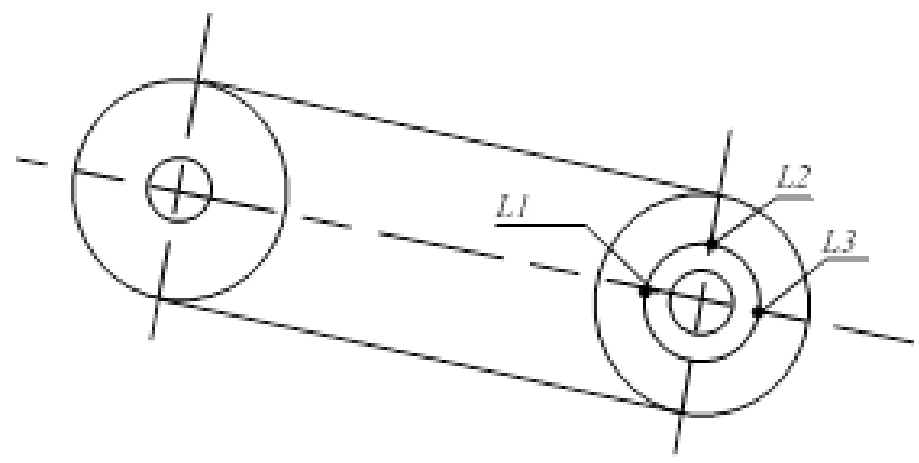

Fig. 2. Bearing vibration measuring points: L1, L2, L3 - accelerometer placed directly on a bearing housing

During the bearing vibro analysis test, the following vibrations were determined: defective ball frequency, rolling through the outer bearing ring, RPI; defective ball frequency, rolling through the inner bearing ring, RPV; frequency of defective balls, RDD; frequency of main vibrations, PVD. Theoretical vibration frequency of defective bearings is calculated according to the kinematic vibration frequency calculation formulas [8].

\section{Results and discussion}

The straw chopper right-hand bearings of the Claas brand combine were measured. This combine harvester straw chopper uses closed-type FAG 20213-K-TVP-C3 bearings.

The following vibration parameters were measured:

1. Root mean square of the vibration velocity RMS V (frequency range 10-1000 Hz);

2. Relative values of the quadratic mean of the vibration acceleration $g$ (frequency range $5-16 \mathrm{kHz}$ );

3. Relative mean values of the quadratic acceleration of vibrations $g$ (frequency range $0.5-16.0 \mathrm{kHz}$ );

During the experimental measurements the following vibration data formats were obtained:

1. Spindle velocity spectra (FFT spectra) frequency range $0-1000 \mathrm{~Hz}$;

2. Spectral acceleration spectra (FFT spectra) frequency range $0-3200 \mathrm{~Hz}$;

3. Vibration velocity spectra (FFT spectra) frequency range $0-6400 \mathrm{~Hz}$;

4. Time curve dependence analysis on oscillation acceleration (ACMT) in 4 second interval.

The bearing defect frequencies were calculated. The calculated bearing defect frequencies are: outer $\operatorname{ring} f_{R P I}=36 \mathrm{~Hz}$, inner ring $f_{R P V}=44 \mathrm{~Hz}$ and ball defect $f_{R D D}=66.7 \mathrm{~Hz}$.

Investigations were carried out in October of 2019, in a farm of Kaunas district. The test was carried out in three harvesters with different working hours. The $1^{\text {st }}$ (new harvester) combine harvester has got 10 working hours, the $2^{\text {nd }}$ one - has got 1236 working hours and the $3^{\text {rd }}$ harvester was with 3590 working hours. The results of the vibration measurement of the harvester shredder bearings are presented in Figures 3, 4, 5.

Experimental data analysis determined which parameter best identifies the developing bearing defects. Figure 3 graph shows the square root of the vibration velocity of the tested $1^{\text {st }}$ (new) combine harvester (frequency range 10-1000 Hz). After performing the analysis using vibration response spectrum, no significant changes in the bearing defect frequencies were observed. This means that the combine straw chopper bearings were relatively new.

Figure 4 shows that using vibration response spectrum, no significant changes in the bearing defect frequencies were observed. The test of the $2^{\text {nd }}$ combine harvester with 1236 working hours straw chopper bearings at oscillation spectrum (FFT spectrum) did not reveal defect frequencies. The amplitude of the acceleration sharply rose up at the frequencies of $47 \mathrm{~Hz}$ and $120 \mathrm{~Hz}$. Since the oscillation frequencies did not coincide with the calculated defective frequencies, it is assumed that this was due on the influence of extraneous oscillation. In case of doubt about the suitability of the bearing use, a different method of diagnosis or the operating temperature of the bearing should be used. 


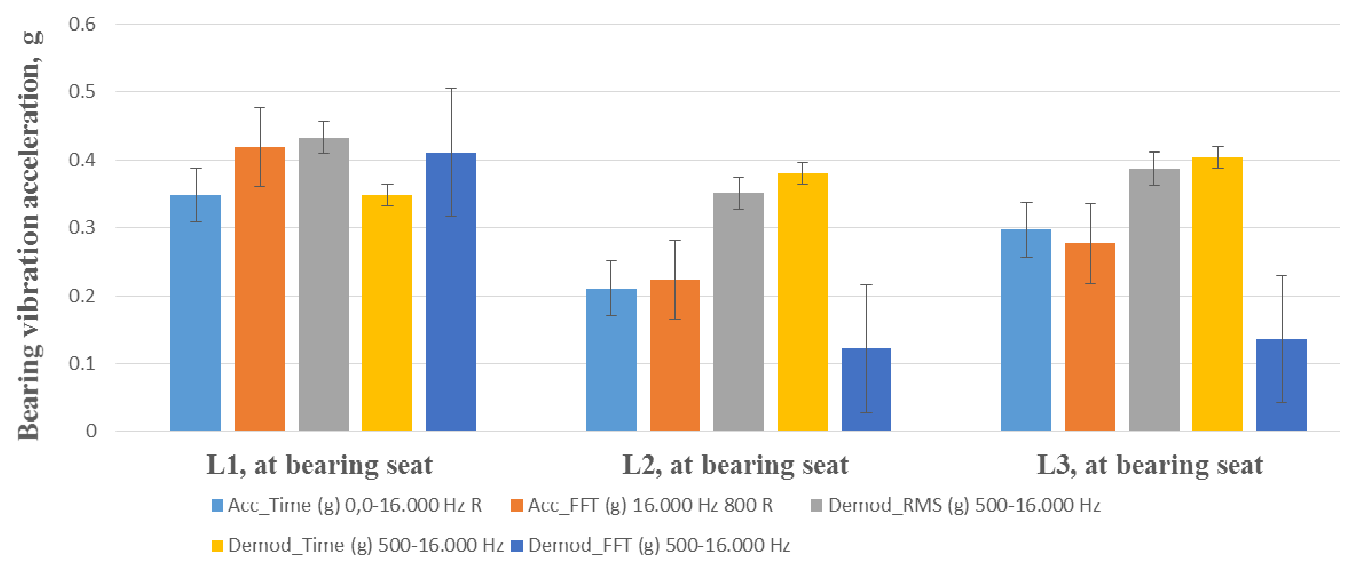

Fig. 3. Straw chopper bearing vibration acceleration graph of $1^{\text {st }}$ (new) combine harvester

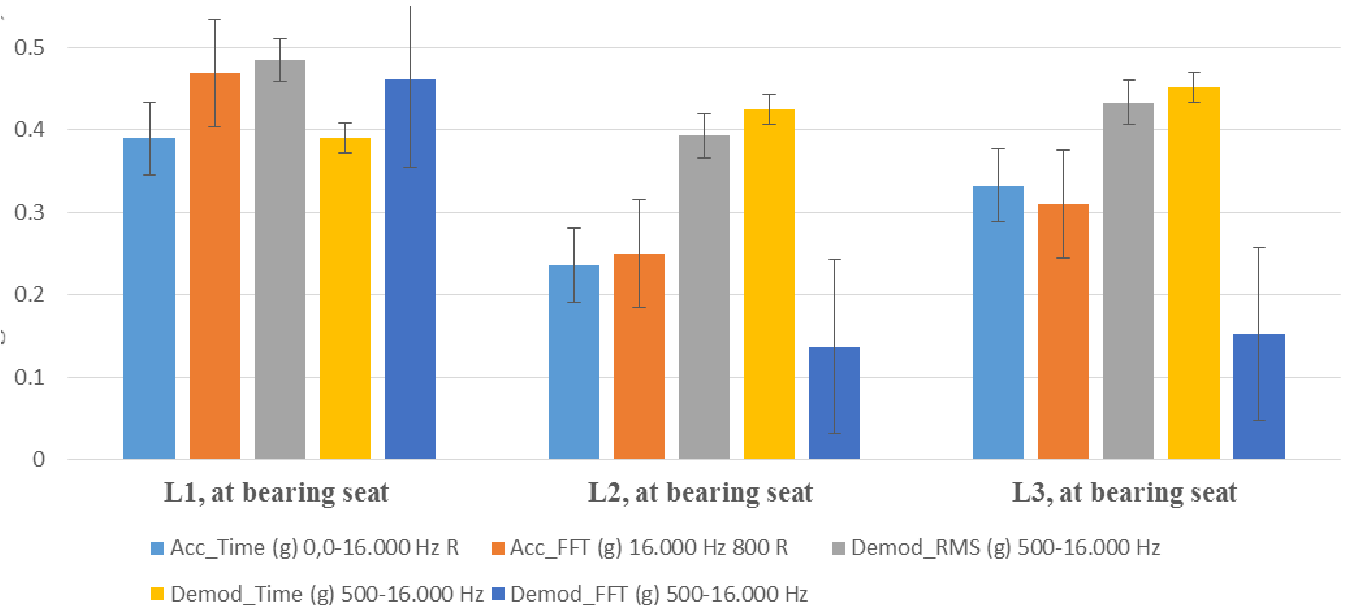

Fig. 4. Straw chopper bearing vibration acceleration graph of $2^{\text {nd }}$ combine harvester

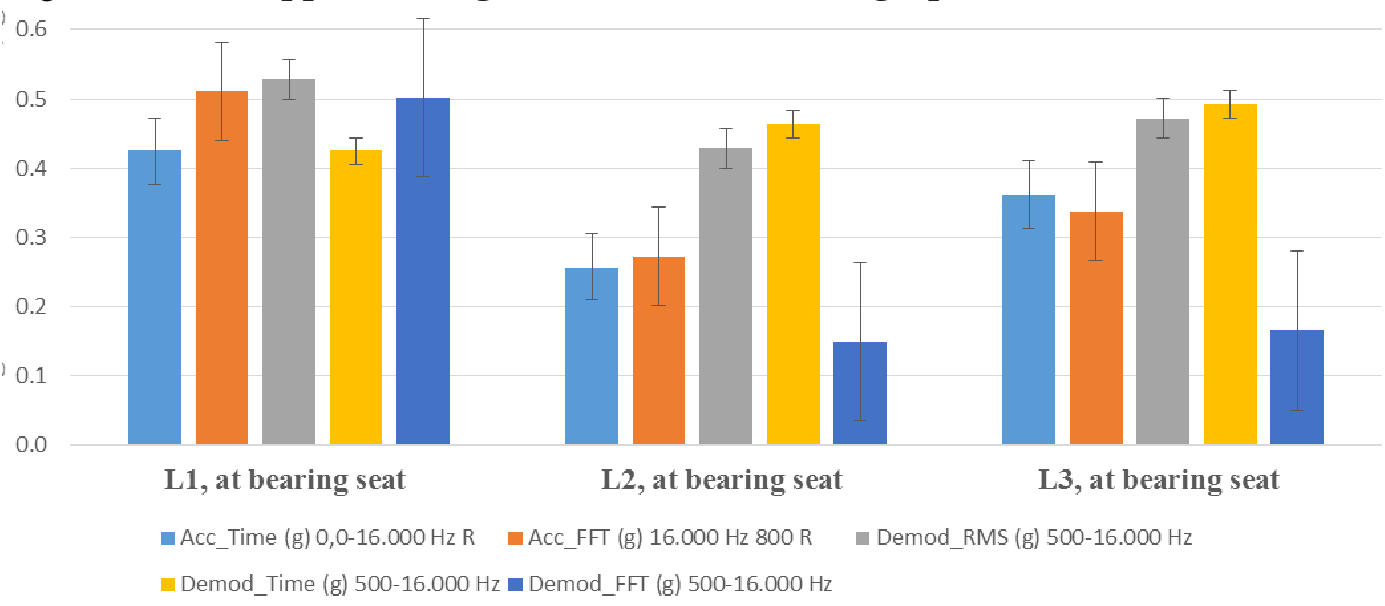

Fig. 5. Straw chopper bearing vibration acceleration graph of $3^{\text {rd }}$ combine harvester

Figure 5 shows the bearing vibration acceleration graphs of the $3^{\text {rd }}$ combine harvester with 3590 working hours. Compared to the straw chopper bearing vibration values of the $1^{\text {st }}$ (new) combine harvester it can be observed that the measured mean RMS values (in the frequency range of 10$1000 \mathrm{~Hz}$ ) of the vibration velocity, the relative values (in the frequency range of 5-16 kHz) of the vibration acceleration in average increased by about $30 \%$. From the obtained data it was possible to evaluate that the bearing can be damaged, because its vibration level is high compared to the bearings of other combine harvesters. However, the analysis of the spectrum of vibration accelerations did not reveal the calculated defect frequencies. The bearing is unlikely to be defective. If there is any doubt about the suitability of the bearing, a different diagnostic method must be used. For the future 
researches it is planned to evaluate the frequency level of used bearings with the defective frequency of new bearings.

\section{Conclusions}

1. The study has shown that the spectral analysis method can detect the bearing defects without disassembling the bearing unit. At full engine speed, the theoretical $400 \mathrm{~min}^{-1}$ bearing rotation was calculated. The obvious defects should occur, when the amplitude of vibrations increases, the bearing balls passing through the outer bearing ring, which theoretical frequency equals $f_{R P I}=36 \mathrm{~Hz}$, the inner $\operatorname{ring} f_{R P V}=44 \mathrm{~Hz}$ and the ball defect $f_{R D D}=66.7 \mathrm{~Hz}$.

2. In the experimental study no straw chopper defect frequencies were observed in all three harvester bearings. However, in the combines with 1236 and 3590 working hours, the straw chopper bearings have shown the increase in vibration acceleration ranged from 12 to $30 \%$.

3. The provided bearing wear estimation method will significantly reduce the time and cost for the failure search without dismounting the bearing units.

\section{References}

[1] Snurov A. Prototype creation of vibroacoustic semi natural signals simulation system of a spindle bearing's defects. Master's thesis project, Kaunas: 2015. 89 p. (In Lithuanian).

[2] Mazeika P. Investigations of diagnostics and fault prevention of roller bearings. Phd thesis. Kaunas: Kaunas technological university, 2008, 130 p. (In Lithuanian).

[3] Randall R. B. Vibration-based condition monitoring: industrial, aerospace, and automotive applications, Chichester: Wiley, 2011. 115 p.

[4] Barzdaitis V., Mazeika P. Diagnostics Practice of heavy duty high speed gear transmissions. Mechanika, vol. 81, 2010, pp. 58-61.

[5] ISO standard 10816-3: Mechanical vibration. Evaluation of machine vibration by measurements on non-rotating parts.Part 3: Industrial machines with nominal power above $15 \mathrm{~kW}$ and nominal speeds between $120 \mathrm{r} / \mathrm{min}$ and $15000 \mathrm{r} / \mathrm{min}$ when measured in situ.

[6] Adash. Users guide Adash 4900 Vibrio M. 65p.

[7] Delvecchio S., Fiorati S., Missoten B., Sas P. Vibro-acoustic signature analysis of the threshing process in harvesting machines. Monitoring and diagnostics of rotating machinery. Proceedings of ISMA 2010, USD, pp. 2815-2830.

[8] Konstantin-Hansen H. Envelope analysis for diagnostics of local faults in rolling element bearings. Application note. Denmark: Brüel\&Kjær, 2010, 8 p. 